Gut, 1978, 19, 327-329

\title{
Secretion of intrinsic factor and hydrochloric acid after 12 weeks' treatment with cimetidine
}

\author{
O. EPSTEIN, ${ }^{1}$ J. JUDELMAN, ${ }^{2}$ G. BEVAN, AND S. ARDEMAN \\ From Edgware General Hospital, Edgware, Middlesex
}

SUMMARY A sample of 16 patients had pentagastrin stimulation studies performed before starting a 12 week course of cimetidine, and again 12 hours after completing the course. Basal and pentagastrin stimulated intrinsic factor secretion was assayed in 13 patients. There was no significant difference in the pattern of secretion after 12 weeks' treatment with cimetidine. The basal and peak acid outputs of all 16 patients were measured. No significant difference was found in the pattern of acid secretion after treatment. It appears that parietal cell secretory function is restored to normal within 12 hours of discontinuing a prolonged course of cimetidine.

Intrinsic factor and hydrochloric acid are secreted by the gastric parietal cells (Hoedemaekar et al., 1964). Pentagastrin, in a dose which causes maximal acid secretion, also stimulates intrinsic factor secretion (Irvine et al., 1968). Cimetidine, an $\mathrm{H} 2$ receptor blocking agent, profoundly affects gastric acid secretion but its effect on intrinsic factor output is less certain. Some short-term experiments have suggested that intrinsic factor secretion is inhibited by cimetidine infusion, while others have shown no effect. No data is available for longer periods of administration of the drug. We have studied the effect of cimetidine on intrinsic factor and $\mathrm{HCl}$ production in patients undergoing treatment for a period of 12 weeks.

\section{Methods}

\section{PATIENTS}

Sixteen patients receiving treatment for duodenal ulceration, duodenitis, and reflux oesophagitis had gastric acid and intrinsic factor secretory studies performed immediately before starting a 12 week course of cimetidine ( $1 \mathrm{~g}$ a day) and again 12 hours after stopping the drug. After a 12 hour fast, a nasogastric tube was positioned fluoroscopically in the most dependent portion of the stomach. The overnight gastric juice was discarded and a basal hour secretion was obtained by aspirating the stomach every 15 minutes. Pentagastrin was then injected

\footnotetext{
1Present address: Medical Unit, Royal Free Hospital, London. Present address: The London Hospital, London SE1. Received for publication 18 December 1977
}

subcutaneously at a dose of $6 \mu \mathrm{g} / \mathrm{kg}$ body weight and samples were aspirated at 15 -minute intervals for a further hour. Intrinsic factor was assayed using the method described by Ardeman and Chanarin (1963). Basal one hour intrinsic factor secretion was measured, as well as total intrinsic factor production in the hour following pentagastrin stimulation. Hydrochloric acid secretion was measured by titration with $0 \cdot 1 \mathrm{~N} \mathrm{Na} \mathrm{OH}$ using a $\mathrm{pH}$ meter. Basal acid output (BAO) and peak acid output (POA) were calculated. Pre- and post-treatment values were compared using the Wilcoxon one sample signed rank test. Blood specimens were tested before and after treatment for haemoglobin, mean cell volume, urea and electrolytes, creatinine, Vitamin $B_{12}$, liver function tests, and parietal cell and intrinsic factor antibodies.

\section{Results}

Intrinsic factor assays were performed on 13 of the 16 patients (Table). No statistical difference was observed between the pre- and post-treatment basal hour or stimulated hour intrinsic factor secretion $(P>0.01)$. Figure 1 represents the mean intrinsic factor response pattern, following pentagastrin stimulation, before and after treatment.

Gastric acid studies were performed on samples obtained from all 16 patients (Table). No statistical difference was observed in pre- and post-treatment BAO and PAO. Figure 2 represents the mean hydrochloric acid response pattern following pentagastrin stimulation before and after treatment.

There was no significant difference between pre- 
Table Effect of cimetidine on basal and pentagastrin stimulated intrinsic factor and $\mathrm{HCl}$ secretion

\begin{tabular}{|c|c|c|c|c|}
\hline & \multicolumn{2}{|c|}{ Pre-treatment } & \multicolumn{2}{|c|}{ Post-treatment } \\
\hline & Mean & Range & Mean & Range \\
\hline \multicolumn{5}{|c|}{$\begin{array}{l}\text { Intrinsic factor output (units/h) } \\
n=13\end{array}$} \\
\hline $\begin{array}{l}\text { Basal hour } \\
\text { Stimulated hour } \\
\text { BAO (mmol) } \\
\text { PAO (mmol) } \\
\text { n }=16\end{array}$ & $\begin{array}{r}2901 \\
13150 \\
3.94 \\
28.45\end{array}$ & $\begin{array}{c}264-11016 \\
2898-26800 \\
0 \cdot 1-13 \\
10-51 \cdot 8\end{array}$ & $\begin{array}{r}2262 \\
17866 \\
2 \cdot 09 \\
26 \cdot 15\end{array}$ & $\begin{array}{c}240-9306 \\
6851-32444 \\
0-4 \cdot 8 \\
9 \cdot 2-42 \cdot 6\end{array}$ \\
\hline
\end{tabular}

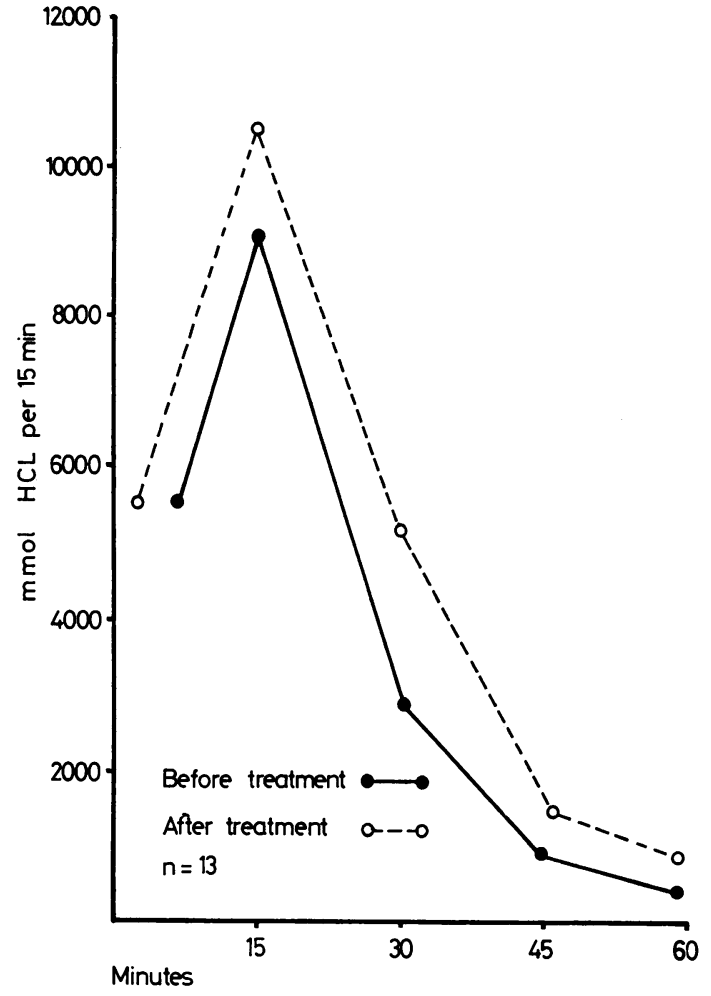

Fig. 1 Pentagastrin stimulated intrinsic factor secretion before and after cimetidine therapy-values represent mean 15 minute output (intrinsic factor units).

and post-treatment values for haemoglobin, mean cell volume, urea and electrolytes, creatinine, or liver function tests. Tests for intrinsic factor and parietal cell antibodies were negative before and after treatment in all 16 patients.

\section{Conclusion}

Previously reported short-term studies of intrinsic factor secretion where cimetidine has been infused during the course of a four-hour pentagastrin stimulation test have yielded conflicting results. Burland et al., in a study on eight normal subjects,

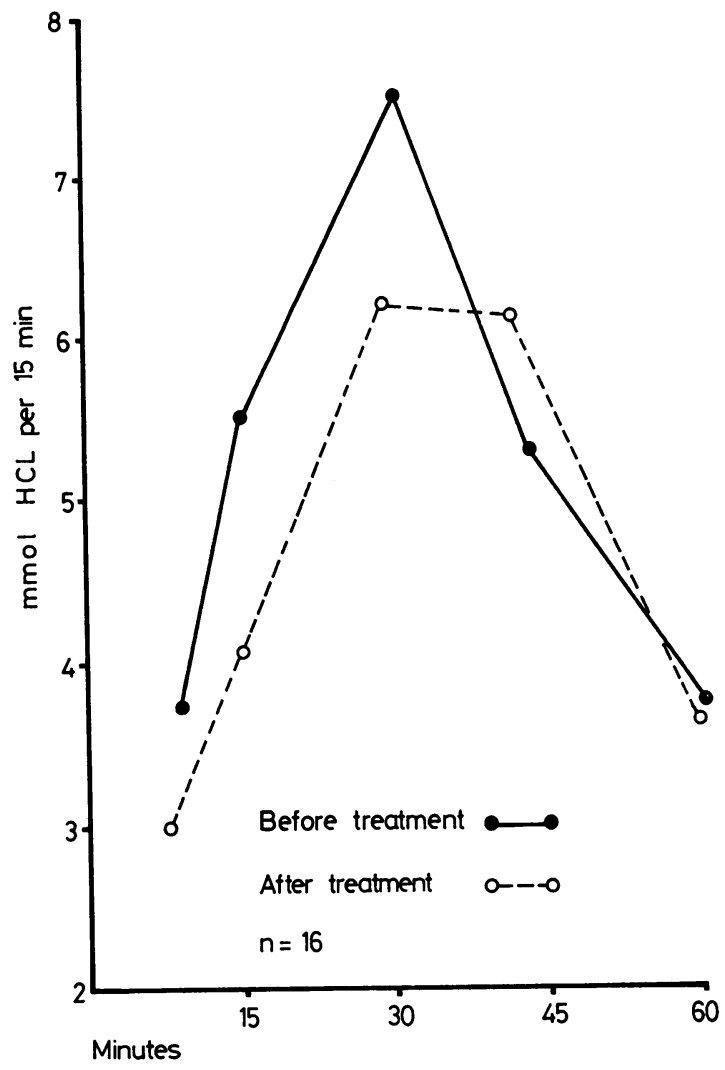

Fig. 2 Pentagastrin stimulated $\mathrm{HCl}$ secretion before and after cimetidine therapy-values represent mean 15 minute output (mmol $\mathrm{HCl}$ ).

found that infusion of cimetidine for 90 minutes had no significant effect on peak concentration, peak output, or pattern of secretion of intrinsic factor (Burland et al., 1977), whereas Fielding et al. demonstrated a significant reduction in both basal and pentagastrin stimulated intrinsic factor production in duodenal ulcer patients during a 60 minute infusion of cimetidine (Fielding et al., 1977). More recently, Sharpe et al. have suggested that the reduction in peak intrinsic factor response to pentagastrin during cimetidine infusion is due to a reduc- 
tion in volume, rather than an alteration in intrinsic factor concentration (Sharpe et al., 1977). The present study demonstrates that cimetidine given continuously for a period of three months has no prolonged effect on parietal cell intrinsic factor production. Normal intrinsic factor output after treatment has ended infers that body stores of vitamin $B_{12}$ will be unaffected by repeated courses of cimetidine.

Holden et al. have demonstrated that gastric acid secretion returns to normal after an eight week course of cimetidine (Holden et al., 1977), which is in contrast to the findings of Spence et al. who reported a significant fall in PAO in patients with duodenal ulcers investigated at least 36 hours after the cessation of a three month course of cimetidine (1.6 g a day) (Spence et al., 1977).

The present study indicates that acid secretion is restored to pretreatment levels within 12 hours of discontinuing therapy. The rapid return of acid production correlates with the fact that a relatively high proportion of patients with duodenal ulcers, successfully treated with cimetidine, become symptomatic again within a month of stopping the drug (Haggie et al., 1976).

\section{References}

Ardeman, S., and Chanarin, I. (1963). A method for the assay of human gastric intrinsic factor and for the detection and titration of antibodies against intrinsic factor. Lancet, 2, 1350-1354.

Burland, W. L., Mills, J. G., Sharpe, P. C., Horton, M. A., and Mollin, D. L. (1977). Proceedings of the Second International Symposium on Histamine H2-receptor Antagonists. Excerpta Medica: Amsterdam.

Fielding, L. P., Chalmers, D. M., Stafford, D. M., and Levi, J. (1977). Proceedings of the Second International Symposium on Histamine H2-Receptor Antagonists. Excerpta Medica: Amsterdam.

Haggie, S. J., Fermont, D. C., and Wyllie, J. H. (1976). Treatment of duodenal ulcer with cimetidine. Lancet, 1 , 983-984.

Hoedemaekar, P. J., Abels, J., Wachters, J. J., Arends, A., and Nieweg, H. O. (1964). Investigations about the site of production of Castle's gastric intrinsic factor. Laboratory Investigation, 13, 1394-1399.

Holden, R. J., Hearns, J. B., McKibben, B., Buchanan, K. B., and Crean, J. P. (1977). Long-term effects of cimetidine on gastric secretion. Gut, 18, A949.

Irvine, W. J., Cullen, D. R., Scarth, L., and Simpson, J. D. (1968). Intrinsic-factor secretion assessed by direct radioimmunoassay and by total-body counting in patients with achlorhydria and in acid secretors. Lancet, 2, 184-188.

Sharpe, P. C., Horton, M. A., Hunt, R. H., Mills, J. G., Vincent, S. H., and Milton Thompson, G. J. (1977). Is intrinsic factor really affected by cimetidine? Gut, 18, A948.

Spence, R. W., Celestin, L. R., and McCormick, D. A. (1977). Proceedings of the Second International Symposium on Histamine H2-Receptor Antagonists. Excerpta Medica: Amsterdam. 